\title{
A New Species of the Genus Pholcus Walckenaer, 1805 (Araneae, Pholcidae) from Hainan Island, China
}

\author{
Yan-Qiu Peng and Feng Zhang \\ College of Life Sciences, Hebei University, Baoding, Hebei 071002, China \\ Correspondence should be addressed to Feng Zhang, dudu06042001@163.com \\ Received 13 January 2011; Accepted 17 February 2011 \\ Academic Editors: K. Cheng and M. Kuntner
}

Copyright ( $) 2011$ Y.-Q. Peng and F. Zhang. This is an open access article distributed under the Creative Commons Attribution License, which permits unrestricted use, distribution, and reproduction in any medium, provided the original work is properly cited.

A new species belonging to the genus Pholcus from Hainan Island, China, is described and illustrated, and under the name Pholcus acerosus sp. nov.

\section{Introduction}

The genus Pholcus was erected by Walckenaer, 1805, with P. phalangioides [10] as the type species. Pholcus is the largest group in the family Pholcidae; up to the present, 171 species have been reported, and of these, 68 species occur in China [1-4].

In China, Hainan Island is the farthest south province and the second largest island after Taiwan, with a land mass of about $34,000 \mathrm{~km}^{2}$. Hainan Island is a vaulted mountain which is high in the middle with lower elevations on its surrounding areas. The climate in Hainan is always high temperature and wet, dry, and rainy seasons are distinct. During expeditions to Hainan Island in 2007, some spider specimens were collected. While examining the Pholcus specimens, we found a Pholcus species that is new to science. We diagnosed, described, and illustrated it under the name Pholcus acerosus sp. nov. in this paper.

\section{Material and Methods}

All measurements are given in millimeters. Carapace length was measured from the anterior margin to the rear margin of the carapace margin, excluding the clypeus. Total length is the sum of carapace and abdomen length, regardless of the petiolus. The measurements of leg I are as follows: total length (femur + patella + tibia + metatarsus + tarsus). All specimens were preserved in $75 \%$ alcohol, examined, illustrated, and measured under a Nikon SMZ1500 stereomicroscope equipped with an Abbe drawing device. Specimens of the new species were deposited in the Museum of Hebei University (MHBU), Baoding, China.

\subsection{Taxonomy}

Pholcus Walckenaer, 1805. Pholcus [4-9]. Type species: Aranea phalangioides [10], by subsequent designation. Diagnosis and description; see [4].

Pholcus acerosus sp. nov. (Figure 1).

2.2. Type Material. Holotype male, China: Hainan Province, Lin'gao County, Mount Gaoshanling $\left(109^{\circ} 69^{\prime} \mathrm{E}, 19^{\circ} 91^{\prime} \mathrm{N}\right)$, 27 July 2007, Feng Zhang leg. Paratypes: $10^{\top}$, 3o, same data as holotype (MHBU).

2.2.1. Diagnosis. Among all three Pholcus species in Hainan Island: Pholcus elongatus, $P$. exceptus and P. gui the new species is similar to $P$ gui in the shape of the procursus, but can be distinguished from the latter by (1) the uncus narrower (Figure $1(\mathrm{~d})$ ), with eight small scales on the edge, (2) the appendix cleaver-shaped, with a medially needleshaped spine from prolateral view (Figures 1(d) and 1(e)), (3) the tip of procursus complicated, with a dark spineshaped process prolaterally (Figure $1(\mathrm{~d})$ ), and a transparent scoop-shaped process distally (Figures $1(\mathrm{~d})$ and $1(\mathrm{e})$ ), and 


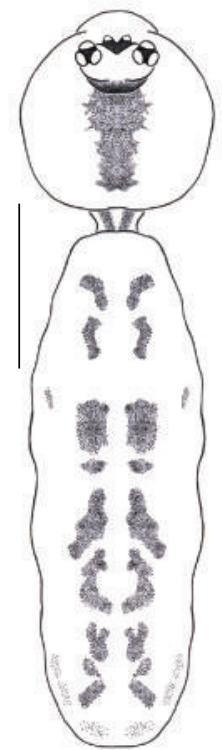

(a)

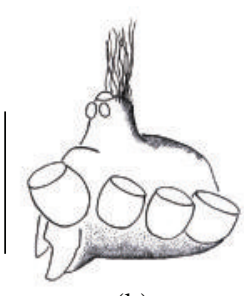

(b)

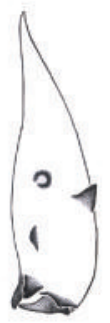

(c)

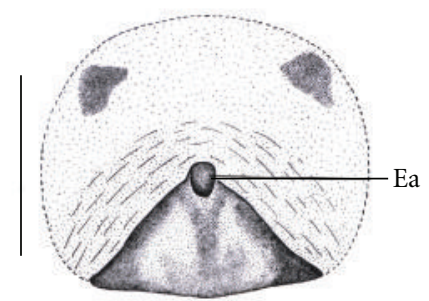

(f)



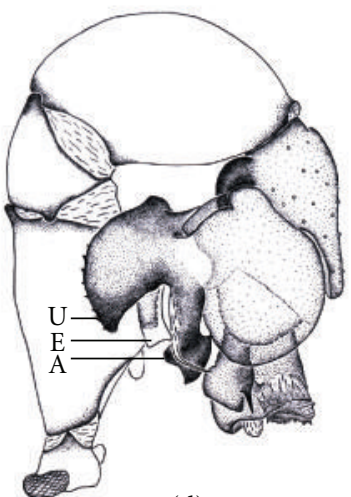

(d) (g)

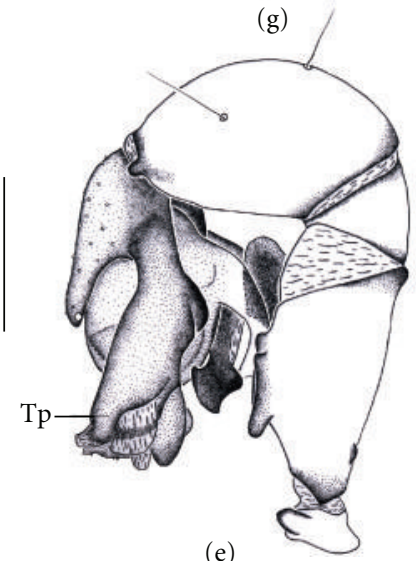

(e)

Figure 1: Pholcus acerosus sp. nov. Male holotype and female paratype. (a) male body, dorsal view; (b) male prosoma, lateral view; (c) male left chelicera, frontal view; (d) left palp, prolateral view; (e) same, retrolateral view; (f) epigynum, ventral view; (g) same, dorsal view. Scale lines: $1.0 \mathrm{~mm}(\mathrm{a}-\mathrm{b}), 0.5 \mathrm{~mm}(\mathrm{c}-\mathrm{g})$.

(4) the broader epigynal apophysis and almost oval wide pore plates (Figures 1(f) and 1(g)).

2.2.2. Etymology. The specific name is derived from the Latin word "acerosus", meaning needle-shaped and referring to the long spine of the appendix.

2.2.3. Description. Male (holotype), total length 4.51: cephalothorax 1.37 long, 1.18 wide; abdomen 3.14 long, 1.10 wide. Leg I: $26.40(6.83+0.55+6.92+10.10+$ 2.00), tibia II: 4.55 , tibia III: 3.10 , tibia IV: 4.46; tibia I L/D: 44.36. Prosoma shape is as in Figures 1(a) and 1(b); Carapace yellowish, with brown radiated stripes in median; yellowish ocular area arose, with triad of eyes on a distinct eye-stalk; clypeus yellowish; sternum brown. Distance AMEAME 0.06. Diameter AME 0.08 ALE 0.18, PME 0.16, PLE 0.16. Chelicerae as in Figure 1(c), with a pair of black serrated apophyses distally, a pair of unsclerotized rounded apophyses proximocentrally, a pair of unsclerotized rounded apophyses proximolaterally, and a pair of triangle-shaped apophyses on the median of the serrated apophyses and the proximocentral apophyses. Legs yellow, but dark brown on patellae and basal part of tibiae, with darker rings on femora and tibiae. Abdomen pale gray, with a few large spots dorsally and laterally as in Figure 1(a). Palps as in Figures 1(d) and 1(e), the trochanter with ventral short apophysis; femur large, with a ventral bulge and a dorsal projection retrolaterally; patella triangular in retrolateral view, and unmodified; tibia swollen, spindle-shaped, and bears two trichobothria laterally and dorsally. Bulb with cleaver-shaped appendix, short embolus and broad uncus, uncus with eight small scales on edge. The tip of the procursus complicated, with a dark spine-shaped process prolaterally and a transparent scoop-shaped process distally.

2.2.4. Variation. Tibia I in the other males: 7.23 . Body length in the other males: 4.81 .

Females in general similar to males. Total length of bodies: 4.85-5.19. A specimen measured total length 5.19: cephalothorax 1.55 long, 1.27 wide; abdomen 3.64 long, 
1.37 wide. Tibia I: 7.55. Distance AME-AME 0.08. Diameter AME 0.09, ALE 0.18, PME 0.16, PLE 0.16. Epigynum roughly triangular as in Figure 1(f), with a water-dropshaped apophysis on the top and a pair of dark triangular shadow. Internal view as in Figure 1(g), with wavy sclerotized arch anteriorly, and a pair of almost oval wide pore plates.

2.2.5. Distribution. Only known from type locality presently.

\section{Abbreviations}

ALE: $\quad$ Anterior lateral eye

AME: $\quad$ Anterior median eye

AME-AME: Distance between AMEs

PLE: $\quad$ Posterior lateral eye

PME: $\quad$ Posterior median eye

A: $\quad$ Appendix

E: $\quad$ Embolus

Ea: $\quad$ Epigynal apophysis

Pp: $\quad$ Pore plates

Tp: $\quad$ Tip of the procursus

$\mathrm{U}$ Uncus.

\section{Acknowledgments}

Dr. J. MacDermott kindly helped reviewing the manuscript. Many thanks are due to two anonymous referees for valuable comments. This work was supported by the National Natural Science Foundation of China (no. 31071885, 31093430) and by the Doctoral Program Foundation of Institutions of Higher Education of China (no. 20091301120005) to Dr. F. Zhang.

\section{References}

[1] S. Q. Li and X. P. Wang, "Endemic spiders in China," 2011, http://www.chinesespecies.com.

[2] N. I. Platnick, The world spider catalog, version 11.5. American Museum of Natural History, 2011, http://research.amnh .org/entomology/spiders/catalog/index.html.

[3] Y. F Tong and L. Z. Ji, "Three new species of the spider genus Pholcus (Araneae: Pholcidae) from Liaodong Mountain, China," Entomologica Fennica, vol. 21, no. 2, pp. 97-103, 2010.

[4] F. Zhang and M. S. Zhu, "A review of the Pholcus (Araneae: Pholcidae) from China,” Zootaxa, vol. 2037, pp. 1-114, 2009.

[5] C. A. Walckenaer, Tableau des aranéides ou caractères essentiels des tribus, genres, familles et races que renfermele genre Aranea de Linné, avec la désignation des espèces comprises dans chacune de ces divisions, Paris, France, 1805.

[6] E. Simon, Histoire Naturelle das Araignées, vol. 1, Roret, Paris, France, 2nd edition, 1893.

[7] B. A. Huber, "New World pholcid spiders (Araneae: Pholcidae): a revision at generic level," Bulletin of the American Museum of Natural History, vol. 254, pp. 1-348, 2000.

[8] B. A. Huber, "The pholcids of Australia (Araneae; Pholcidae): taxonomy, biogeography, and relationships," Bulletin of the American Museum of Natural History, vol. 260, pp. 1-144, 2001.

[9] J. L. Hu, Spiders in Qinghai-Tibet Plateau of China, Henan Science and Technology Publishing House, Zhengzhou, China, 2001.
[10] J. C. Fuesslin, "Verzeichnis der ihm bekannten Schweizerischen Insekten, mit einer ausgemahlten Kupfertafel: nebst der Ankündigung eines neuen Inseckten Werkes," Zürich and Winterthur, p. 62, 1775. 

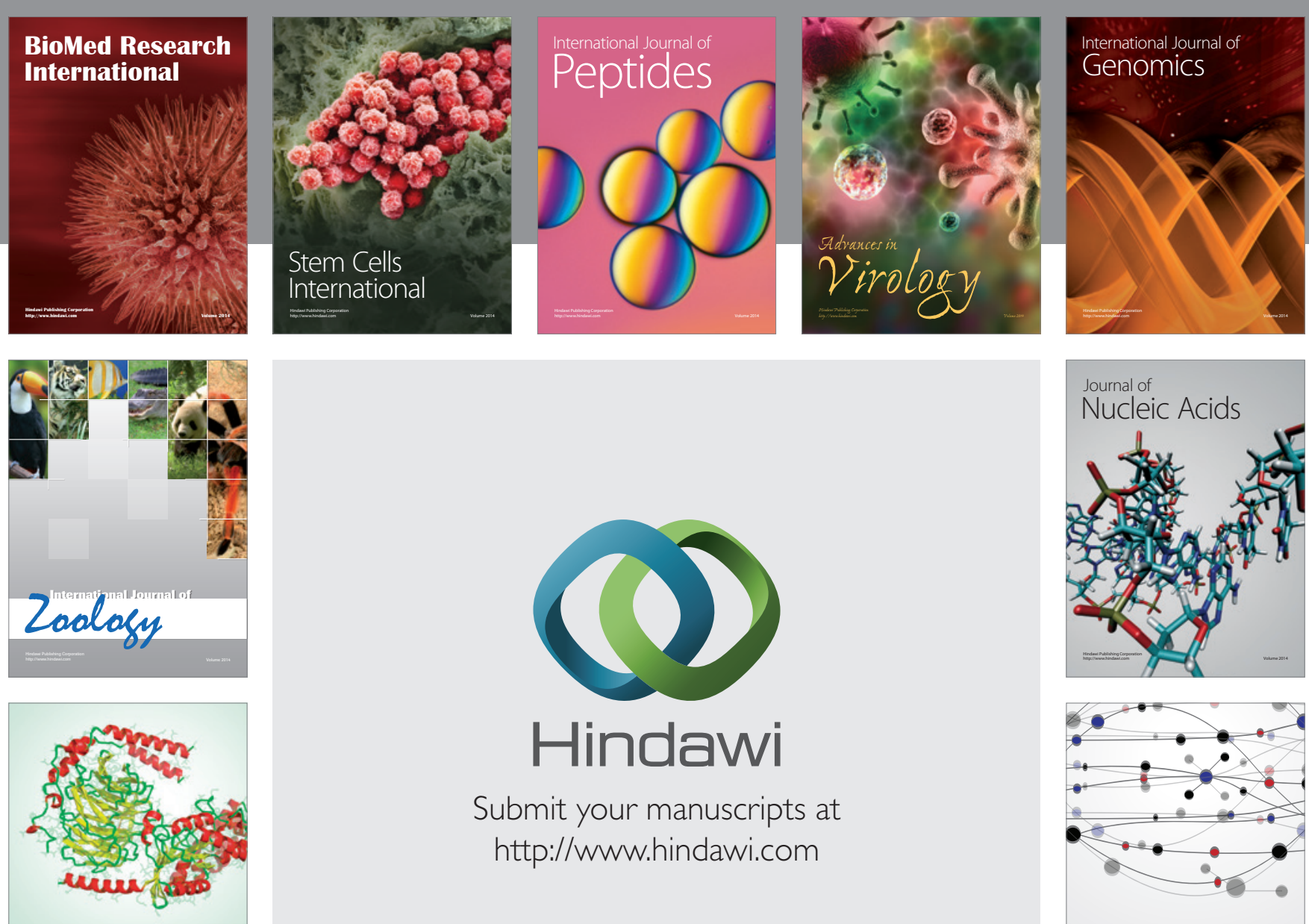

Submit your manuscripts at

http://www.hindawi.com

Signal ${ }^{\text {Jumal }}$ Transduction
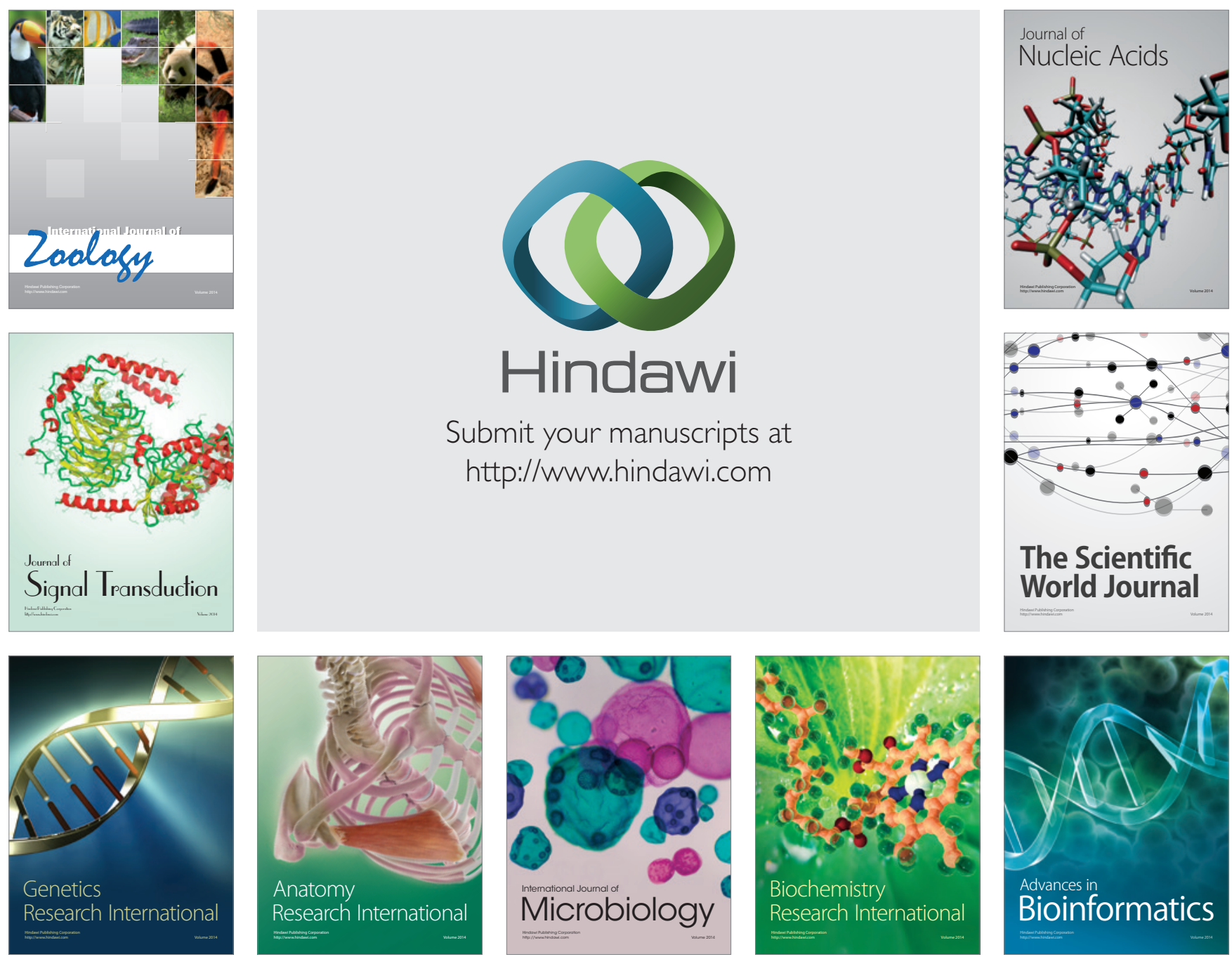

The Scientific World Journal
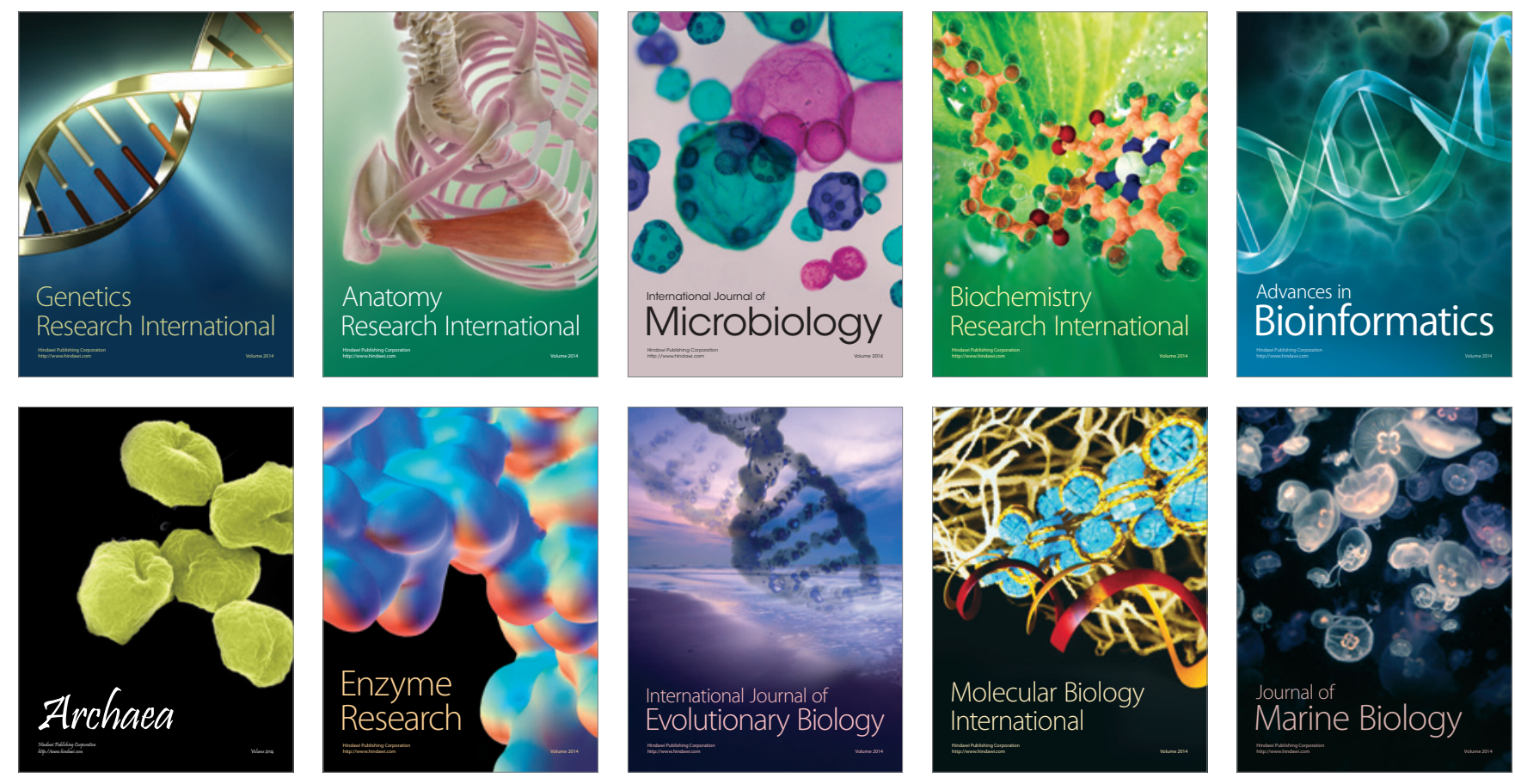